Article

\title{
Development of an Active Power Reserve Management Method for DC Applied Wave-Wind Combined Generation Systems
}

\author{
Seungmin Jung ${ }^{1}$, Yeuntae Yoo ${ }^{1}$, Hyunwook Kim ${ }^{1}$, Jae-Hyeong Lee ${ }^{1}$, Minhan Yoon ${ }^{2}$ and \\ Gilsoo Jang ${ }^{1, *}$ \\ Received: 27 August 2015 ; Accepted: 22 October 2015 ; Published: 4 November 2015 \\ Academic Editor: John Ringwood \\ 1 School of Electrical Engineering, Korea University, Seoul 136-713, Korea; muejuck@korea.ac.kr (S.J.); \\ yooynt@korea.ac.kr (Y.Y.); khw0725@korea.ac.kr (H.K.); bluesky6774@korea.ac.kr (J.-H.L.) \\ 2 Department of Electrical and Computer Engineering, Seoul National University, Seoul 151-742, Korea; \\ minhan.yoon@gmail.com \\ * Correspondence: gjang@korea.ac.kr; Tel.: +82-2-3290-3246; Fax: +82-2-3290-3692
}

\begin{abstract}
A system that combines a wind turbine and a wave generator can share the off-shore platform and therefore mix the advantages of the transmission system construction and the power conversion system. The current hybrid generation system considers output limitation according to the instructions of the transmission system operator (TSO), and controls the profile using wind turbine pitch control. However, the integrated wave generation system utilizing a DC network does not adapt a power limitation scheme due to its mechanical constraints. In this paper, a control plan focusing on the electrical section of wave generators is formed in order to effectively manage the output profile of the hybrid generation system. The plan pays attention to power reserve flexibility for the utility grid using the analysis of the controllable elements. Comparison with the existing system is performed based on real offshore conditions. With the help of power system computer aided design (PSCAD) simulation, the ability of the novel technique is estimated by proposing the real power control based on the reference signal of TSO and the reactive power capacity it produces.
\end{abstract}

Keywords: combined source; voltage sourced converter (VSC); reactive power reserve (RPR); DC network; wave-offshore

\section{Introduction}

Interest in the study of auxiliary equipment and integration technology regarding a variety of distribution generators is steadily increasing in line with the interest in sustainable and renewable energy sources. In terms of renewable energy sources, technical research is underway to be able to perform output power control and ancillary services such as low voltage ride through and voltage control by composing clusters mainly based on wind generators [1,2]. Among these studies, the offshore wind industry has continuously sought to increase efficiency by installing turbines at sea, in which efforts have been made to improve the availability of electrical equipment for cluster infrastructure or the suitability of power extraction from wind energy [3]. However, it is necessary to solve the problems of the electric system configuration cost regarding the internal grid, and further environmental variables (such as wind forecasting) need to be considered according to the wide range operating conditions when developing a large-scale wind farm. In addition, general wind farms demand management systems that can handle whole wind turbines within the designated conditions. These systems have real power (active power) limitation processes installed to satisfy the reference signal generated by the transmission and system operator (TSO) for a grid operating 
condition. Additional reserve sources to accommodate abnormal output power variation is also debated between TSO and the system owner [4]. Finally, in the case of a wind power generator composed of an induction generator, the reactive power compensation must be considered in order to consider the regarded operating condition such as black-start. The voltage management and related reactive power supply are classified as ancillary services and the capability of reactive power should be continuously reported to the system operator for secure and reliable system operation.

To address such problems, the research for accessory cooperation using other distributed energy sources is carried out continuously with wind energy as the focus [5]. In order to reduce the real power output variations, an energy storage system (ESS) can be applied to wind farms over a certain size [6]. In the case of reactive power control, it is possible to control the voltage at the point of common coupling (PCC) by integrating compensation devices such as static var compensator (SVC) for the exact voltage. However, these devices have considerably high costs and therefore they have usually only been considered in large-scale wind farms.

As the interest in renewable energy sources has recently increased, novel research areas have appeared, not only about improving the efficiency of existing renewable sources, but also about forming a combined generation system that can lead to construction cost minimization. Each combined generation technology focuses on improving the reliability issues of renewable sources, which can affect not only the power supply plan but also the voltage fluctuation of the utility grid $[7,8]$. By paying attention to the two aspects above, a feasibility analysis about wave-wind combined farms and further pre-investigations including electrical integration strategy are being progressed [9]. As a new concept, a wave combined power generator system is being considered in the wind energy field due to the effectiveness of developing a combined system in offshore regions [10].

This paper deals with a designed hybrid generation system (HGS) that is built on a shared offshore platform for economic advantage. The system is currently being studied and has a unique output power characteristics as it is composed of several wave and wind systems. This unusual system structure is a major consideration for this paper because each unit in the HGS is not considered as an individual controllable unit by TSO, and the management system can control the available power with certain purpose. Basically, however, the concept of HGS is founded on utilization of renewable generation systems becoming commercialized (the design process does not focus on design of whole new generation systems), and the HGS deals with appropriate electrical control methods for its own interconnected system. In case of wind generators, an active curtailing of real power is possible according to the received order with its own pitch system. On the contrary, there is no way to control the total output profile at a wave generation system except for tripping certain units because they were originally designed to have small generation capacity and follow the maximum generating point.

We discuss a real power control method in the DC section of a wave generation system to handle the output power of entire generators with a designated objective function. The proposed control method will be established for maximizing real power control flexibility and be applied to the reactive power control process as an exemplary application case. The power control method by adopting controllable devices like variable resistance or ESS has been utilized in several railway systems through DC power flow analysis [11]. In case of railway systems, however, individual generation systems were not considered in the entire process because of the absence of positive source, and the analysis is not focused on the power profile of a single connection point like the proposed method. With the reformed proposed method in this paper, new application could be introduced in DC section by focusing on the power profile of DC-based generation systems at the connection point. The processes will be verified through the transient simulation tool with the following considerations:

- The designed HGS utilizes a doubly-fed induction generator (DFIG). In the simulation, the DFIG adapts power factor control logic regarding the reactive power generation. 
- The DC section's power limitation method and logic with a controllable device will mainly be checked in this paper because the present system does not adopt real power control and the entire output profile of HGS could be limited by wind turbines. By considering the voltage variation of the inner system, a variable resistance operation plan will be formulized. The conceptual plan is represented in Figure 1 and the variable resistance can be replaced with other controllable devices such as ESS. We utilize the device to check the availability of the power control scheme in DC section.

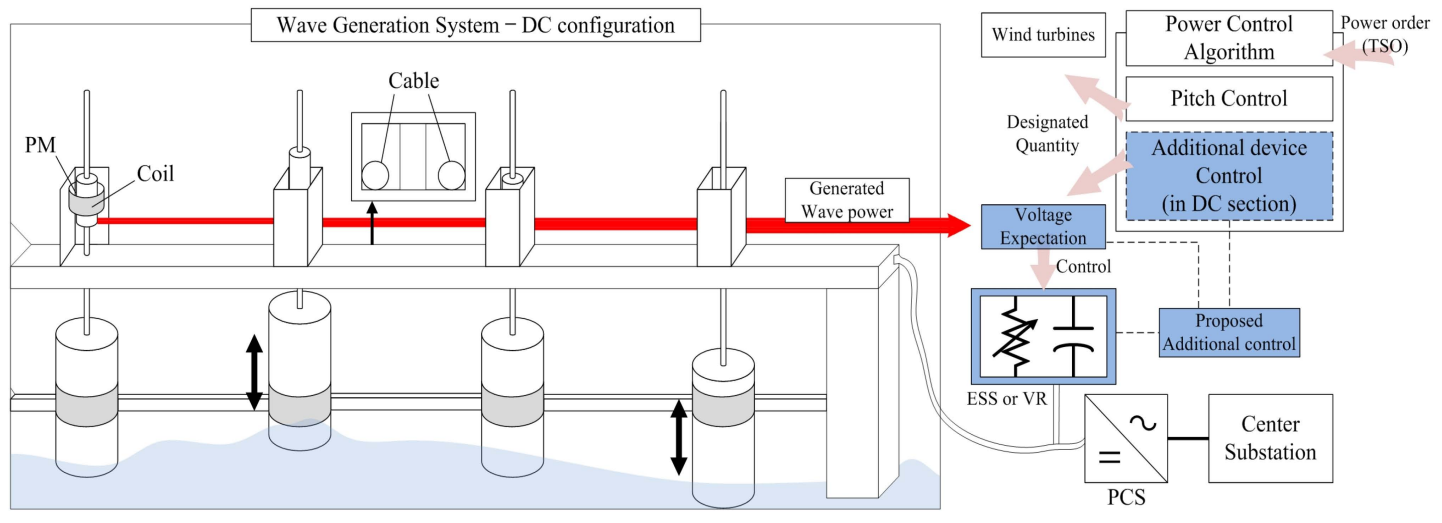

Figure 1. Applied wave generation system and the concept of the proposed power control algorithm. PM: permanent magnet; VR: variable resistance; PCS: power conversion system.

- Reactive power control would be executed according to the system order. If the TSO wants to maximize the available reactive power due to a system constraint such as low voltage conditions, the operation mode can be changed with the proposed method.

\section{System Description}

\subsection{Wave-Offshore Hybrid System}

The wave-offshore combined system is a planned system for reducing construction costs and efficiently uses both the power conversion system (PCS) and transformer by building a number of wind turbines and wave generators on one platform. Recently, the main concept of this system has been formulized with higher capacity than the previously designed systems. The total size of the floating structure in the ongoing project is expected to be over $200 \times 200 \mathrm{~m}^{2}$ and all of the required electricity devices could be placed on the structure. The DFIG wind turbine and permanent magnet linear synchronous generator (PMSLG) wave generator are the main devices of the proposed system, and the generated power can be transferred to the utility grid through the inner transfer system. Using a step-up transformer located at the center of the platform, the voltage level is changed and transferred to the interconnection point. The wave power generators are integrated in each corner of the rectangular portion of structure. Through the DC conversion process in an individual convertor, the electricity generated by the wave power generator is transferred to the $\mathrm{AC}$ conversion process at the integrated PCS at the middle of the structure. The wave generators are composed of four arrays in the floating structure and are divided into two different groups to connect each group on PCS by thicker cable to reduce the cable cost.

As the demonstration project considers four wind turbines, the total generator system now needs to accommodate 10.4 MW with the combined wave generation system [12]. Since the capacity of the proposed generator is relatively greater than that of the previous distribution generator, the system should follow the limitation order of TSO and the output power of each generator should be controlled according to the reference signal. Figure 2 presents a conceptual image of the HGS and the flow of the generated power described in this paper. The control signal for the entire system is based 
on the output profile of the central transformer, and the output power of each generator is controlled to match the entire reference signal. The output profile of the entire system is designated according to the order of the TSO, and the real power will be limited by controlling other mechanical properties if the amount exceeds the reference signal. The process involves pitch control for individual wind turbines to reduce output power. However, the wave generation system does not adopt the power limitation method in the present state, and the generator follows the maximum power point tracking (MPPT) process.

Figure 3 presents the PCS system in the HGS. Each converter for a single PMSLG regulates the output power to send it to the grid through the DC system. The HGS adopts a common converter system that includes a 2 MVA grid-side DC/AC inverter. The available reactive power of the voltage sourced converter (VSC) is changed with the profile of the real power of wave generation system [13]. Thus, the imposing power control system is worthwhile when the grid demands additional reactive power compared to normal state.

Some controllable devices including ESS can be included in this system, but the voltage fluctuation due to the generation system should be analyzed appropriately because the controlled quantity is affected by the voltage variation [14]. The length of the DC section is relatively long because the HGS is usually designed by considering the separation distance of each wind turbine. Therefore, the proposed system will consider the power control method while maintaining the voltage level in the DC section to ensure the wave generator system can control the available reactive power.

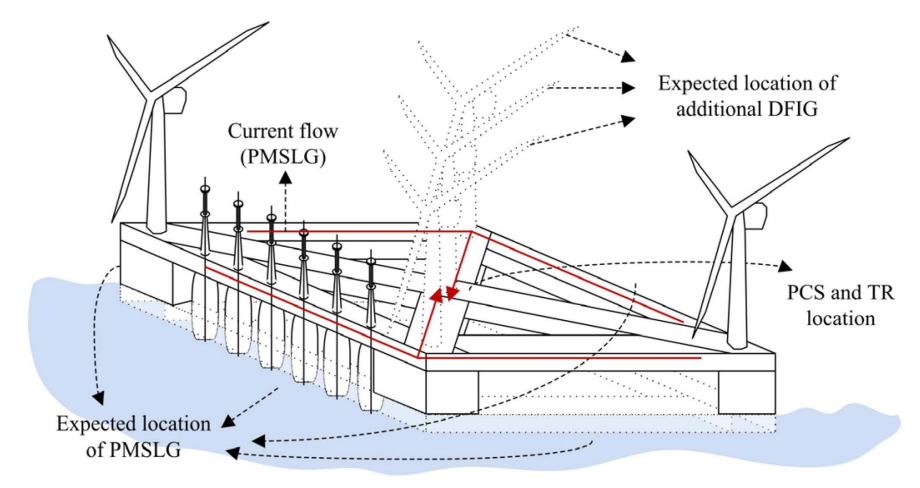

Figure 2. Concept of the wave-offshore hybrid generation system. TR: transformer.

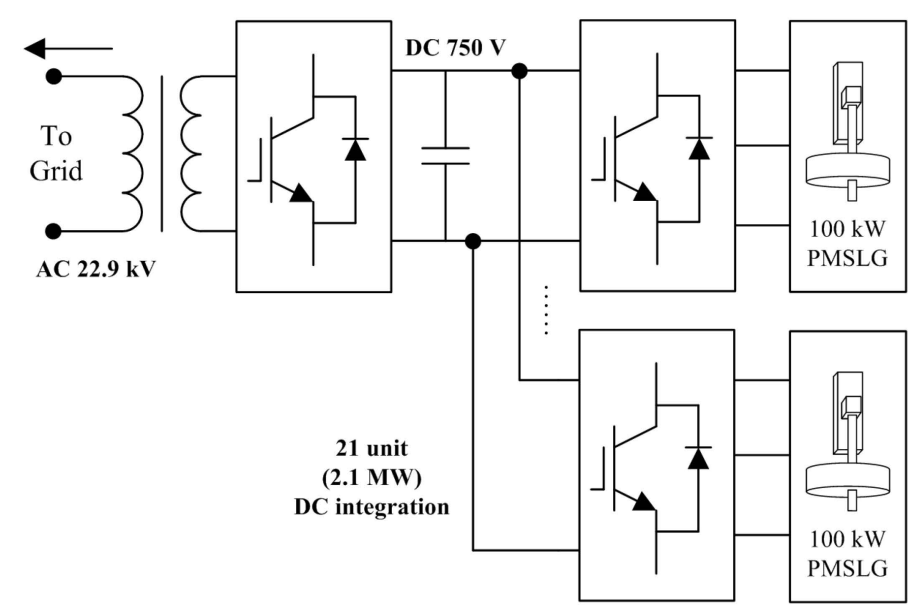

Figure 3. Low voltage DC system for wave generators. 


\subsection{Doubly-Fed Induction Generator (DFIG) Wind Generation System}

The DFIG wind power generation system allows variable speed operation in a large but limited range. The rotor-side converter compensates for the difference between the mechanical and electrical frequency by using rotor current injection. The power control of DFIG is operated according to its own controller, depending on the system condition, including the system faults.

The back-to-back converter is developed to control the real and reactive power by controlling the DC-link voltage for ensuring a DFIG operation with a certain power factor. The stator-side converter maintains the DC-link voltage constantly, regardless of the magnitude and phase of the real power. A detailed analysis of the stator-side convertor control was provided in previous studies [15].

The pitch controller is used when the wind speeds are above the rated wind speed of the turbine drive or the output profile of the wind turbine is above the reference signal. In the control process, the generated power is held at a certain point and the blade pitch angle is changed in order to limit the aerodynamic efficiency of the turbine. These mechanical controls prevent damage caused by the high rotor speed and allows the system owner to limit the output power.

\subsection{Reactive Power Reserve of the Wave System}

When analyzing the PMSLG which can comprise a system with a large capacity, it is possible to combine many wave power generators through a DC link, and the benefits in terms of efficiency and control of the structure of the PCS can be achieved with the construction of a single module. The DC current would be changed into AC form at the center power station, the composed DC section in the system is operated as a kind of low voltage distribution system [16]. The VSC has the advantage of executing reactive power control continuously by focusing on the system order. To preserve the security of the utility grid, a sufficient reactive margin is required to high-capacity generator and a reactive power reserve (RPR) is formulized as a control value in the generation system $[17,18]$. Based on these points, the mentioned combined system can provide further reactive power compared to the conventional distribution systems and it can offer more flexible reactive power control for the system operator.

In the case of the wave-offshore HGS, advanced control logic is required for each generator because the expected reserve powers of each generation system are not equal. Moreover, the HGS has unique characteristics in terms of grid code because every requirement concerning the distribution system would be applied on the connection point of HGS as a single generation system. Since the wind and wave systems have different RPRs, the control logic of these combined systems should consider the effective margin that is necessary to the utility grid $[19,20]$.

Unlike the current power flow formulation, which does not include the RPR control method, the proposed control method includes an algorithm to maximize available reactive power based on the formulized real power control method.

\subsection{Model with Wave Generators}

A number of wave generators are designed with a central control topology, which includes a shared DC section [21]. Each connection point's voltage of the generator differs according to the generating profile. These condition can be obtained by performing an analysis of the energy flow regarding the system configuration. Figure 4 presents the designed electrical structure of the HGS. The problem of power control involves determining the location and line components that can affect the voltage variation. The model described in this paper explicitly assumes the multi-feed DC system, and the focus is the real power flow including loss at the DC section. When the number of the wave generator is considered as " $n$ ", the power flow of the array can be defined as follows:

$$
P_{\text {array }}=\sum_{n=1}^{\mathrm{N}} P_{n}-\sum_{n=1}^{\mathrm{N}} P_{\text {loss }}(n)
$$


where $P_{\text {array }}$ is the total output power of the array; $P_{n}$ is the output power of wave generator; $P_{\text {loss }}$ is the loss by the cable components and $\mathrm{N}$ is the total number of wave generator in the array. The output power of wave generator and the cable loss can be defined as follows:

$$
\begin{gathered}
P_{n}=\gamma A_{\mathrm{fac}} \dot{x}_{n}^{2} \\
P_{\text {loss }}=r_{n n+1} \frac{P_{n n+1}^{2}}{V_{n}^{2}}
\end{gathered}
$$

where $\gamma$ is the velocity dependent damping function; $A_{\text {fac }}$ is the active area of the stator; $x_{n}$ is the buoy displacement from central position; $P_{n n+1}$ is the real power which flows that goes from bus $n$ to bus $n+1, r_{n n+1}$ is the resistance between bus $n$ to bus $n+1$ and $V_{n}$ is the bus voltage magnitude. We adapt the damping function and $A_{\mathrm{fac}}$ by utilizing linearized generator function as below [22]:

$$
\begin{aligned}
& \gamma=\frac{3}{r_{g}}\left(\frac{V_{g}}{\dot{x}_{n}}\right)^{2} \\
& A_{\mathrm{fac}}=\left\{\begin{array}{cc}
0, & \left|x_{n}\right| \geqslant 0.5\left(l_{\mathrm{p}}+l_{\mathrm{s}}\right) \\
1, & \left|x_{n}\right| \leqslant 0.5\left(l_{\mathrm{p}}-l_{\mathrm{s}}\right) \\
1 / l_{\mathrm{s}}\left[0.5\left(l_{\mathrm{p}}+l_{\mathrm{s}}\right)-\left|x_{n}\right|\right], & \text { else }
\end{array}\right.
\end{aligned}
$$

where $V_{\mathrm{g}}$ is the effective voltage drops over the resistances of the generator $\left(r_{\mathrm{g}}\right) ; l_{\mathrm{s}}$ and $l_{\mathrm{p}}$ are stator and piston lengths.

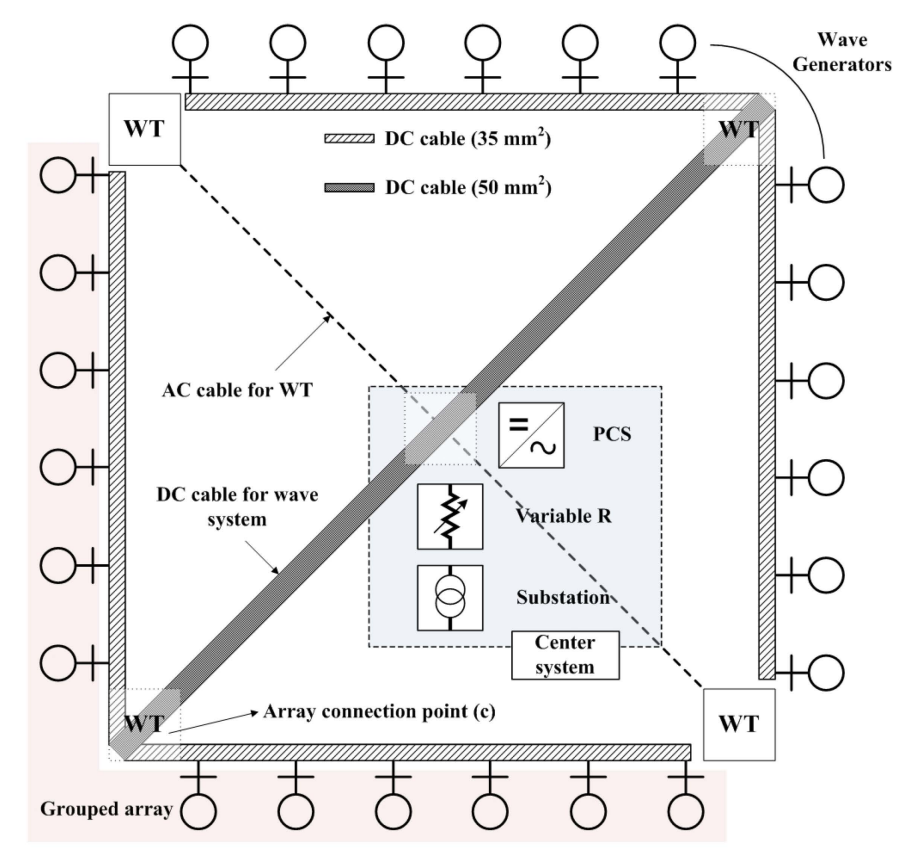

Figure 4. Electrical system structure of hybrid generation system (HGS).

To describe the generated power that is transferred to the grid, the residual power flow equation should be formulated. By adopting the connection point, the total transferred power to the main conversion station can be represented as follows:

$$
P_{\mathrm{pcs}}=\sum_{i=1}^{\mathrm{I}} P_{\text {array } \cdot i}-\sum_{i=1}^{\mathrm{I}} P_{\text {loss }}(i)
$$

where $P_{\mathrm{pcs}}$ is the total power flow to grid; $i$ is the number of array and $\mathrm{I}$ is the total number of array. 
The real power is obtained by differentiating the magnetic flux in the linear piston according to the up-and-down motion of the buoy. Within the available range of the piston's height, the maximum available power is chosen as the reference signal for the generator-side converter for each wave generator. Only the MPPT control is available in the linear wave generation system and other additional control devices should be composed to limit the generated output power. This paper considers the variable resistance in the DC section as a controllable device. When the total output power of the wave generator exceeds that ordered by the operator, then the variable resistance is activated to subsequently reduce the power transferred to the grid. Therefore, we can set the total wave power as a reference and apply it to the circuit analysis plan to expect voltage fluctuation as shown in Equation (7). Additionally, the DC current flow to grid can be represented by using the ordered quantity for wave system and own admittance of PCS as shown in Equation (8):

$$
\begin{gathered}
P_{\text {order }}=\sum_{i=1}^{\mathrm{I}} P_{\text {array } \cdot i}-\sum_{i=1}^{\mathrm{I}} P_{\text {loss }}(i)-P_{\mathrm{vr}} \\
i_{\mathrm{dc}}=\sqrt{g_{\mathrm{eq}} \cdot P_{\text {order }}}
\end{gathered}
$$

where $P_{\text {order }}$ is the real power order for wave generation system; $P_{\mathrm{vr}}$ is the absorbed quantity by variable resistance; $i_{\mathrm{dc}}$ is the DC current flow to inverter and $g_{\text {eq }}$ is the equivalent admittance of PCS.

The DC side voltage variation fully depends on the output profile of the wave generators. If the operator wants to control the variable devices appropriately, the voltage variation by the power profile needs to be precise.

\section{Power Control Algorithm}

\subsection{Circuit Analysis}

It is possible to calculate the maximum controllable amount of power based on the DC circuit analysis, and the appropriate resistance value to achieve the process. Figure 5 shows the simplified model of the DC section of the HGS. In the PCS, the capacitance is maintained constantly and it can be represented as a constant voltage source. With the operation of wave generators, the generated power is transferred to the voltage source (the current " $i_{\mathrm{dc}}$ " is flowed to the PCS). At this time, if the transferred power by reflecting the occurred loss exceeds the reference quantity for the wave generation system, the variable resistor is applied to absorb the overhead power. Therefore, the expected voltage variation due to the real power flow should be continuously checked for absorbing the designated real power quantity with the appropriate resistance value. The calculated value is co-operated with PI controller reflecting controllable range because the variable resistance is generally regulated based on a stepped control. Figure 6 shows the equivalent circuit of the schematic map in Figure 5. The voltage source is alternated with the current source for circuit analysis. The connection point is expressed as a node in the equation for analyzing the output power of both side wave generators, incorporated separately for a different array. From the represented network, the node equation can be derived as shown in Equation (9):

$$
\left|\begin{array}{cccccc||c|c}
g_{1}+g_{12} & -g_{12} & 0 & 0 & 0 & 0 \\
-g_{12} & g_{2}+g_{12}+g_{2 c} & 0 & 0 & -g_{2 c} & 0 \\
0 & 0 & g_{3}+g_{34} & -g_{34} & 0 & 0 \\
0 & 0 & -g_{34} & g_{4}+g_{34}+g_{4 c} & -g_{4 c} & 0 \\
0 & -g_{2 c} & 0 & -g_{4 c} & g_{T 1}+g_{2 c}+g_{4 c} & -g_{T 1} \\
0 & 0 & 0 & 0 & -g_{T 1} & g_{T 1}+g_{v r}+g_{\mathrm{eq}}
\end{array} \| V_{1}\right|\left|\begin{array}{l}
0 \\
V_{2} \\
V_{3} \\
V_{4} \\
V_{c} \\
V_{\mathrm{pcs}}
\end{array}\right|=\mid \begin{aligned}
& 0 \\
& 0 \\
& 0 \\
& 0 \\
& I_{\mathrm{dc}}
\end{aligned}
$$

where $g_{n}$ is the equivalent admittance of generators; $g_{i j}$ is the line admittance between bus $i$ and $j$ and $g_{\mathrm{vr}}$ is the equivalent admittance of variable resistance. 


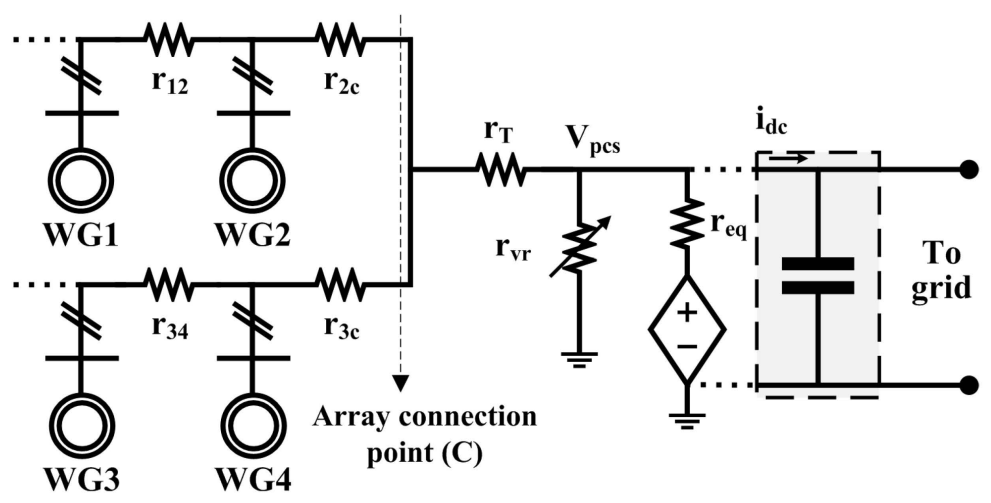

Figure 5. Schematic map of DC section in the proposed system.

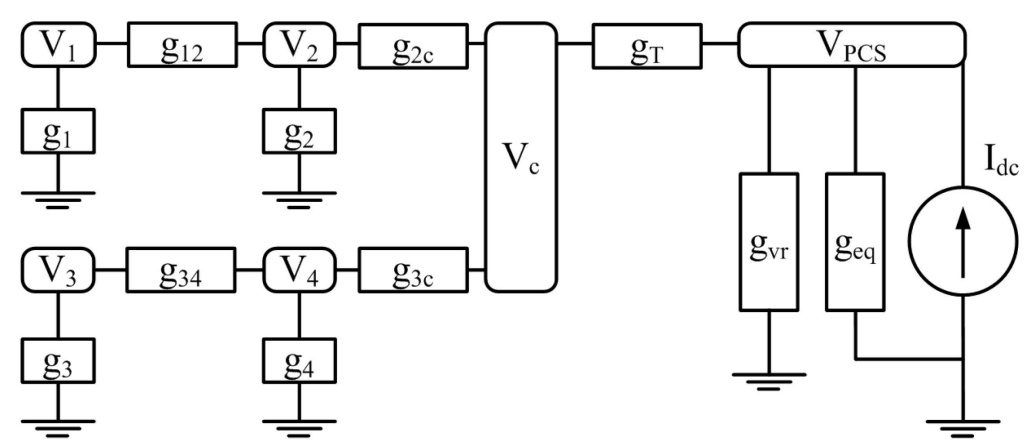

Figure 6. Equivalent circuit of DC section.

In the circuit analysis of the HGS, a number of admittance values are shown and they differ from the voltage change during the operation. In order to reflect this, an iterative calculation method is introduced with some designated values. The initial admittance of the variable components is generated firstly with initial voltage of the system and can be changed depending on the voltage variation of the iteration process. The equivalent admittances of variable resistance is defined in Equation (10):

$$
g_{\mathrm{vr}}=\frac{P_{\mathrm{vr}}}{V_{\mathrm{pcs}}{ }^{2}}
$$

In the circuit analysis, the generators act as a negative resistance because the equivalent generator only generates power with the voltage state. The relation between the voltage and equivalent admittances of each wave generator is defined in Equation (11):

$$
g_{n}=-\frac{P_{n}}{V_{n}^{2}}
$$

Since $I_{\mathrm{dc}}$ has been determined according to the real power order, the solution of the voltage at each node can be obtained using an iteration process. The equation used in the iteration is presented as below:

$$
[V]=[g]^{-1} \times[I]
$$

When the power flow analysis is performed for the actual system based on Equations (9) and (12), the size of the conductance matrix by considering the wave generators is "PCS + array connection points + wave generator" (in case of HGS, the size will be $27 \times 27$ matrix). The entire power flow and voltage expectation process are represented in Figure 7. 


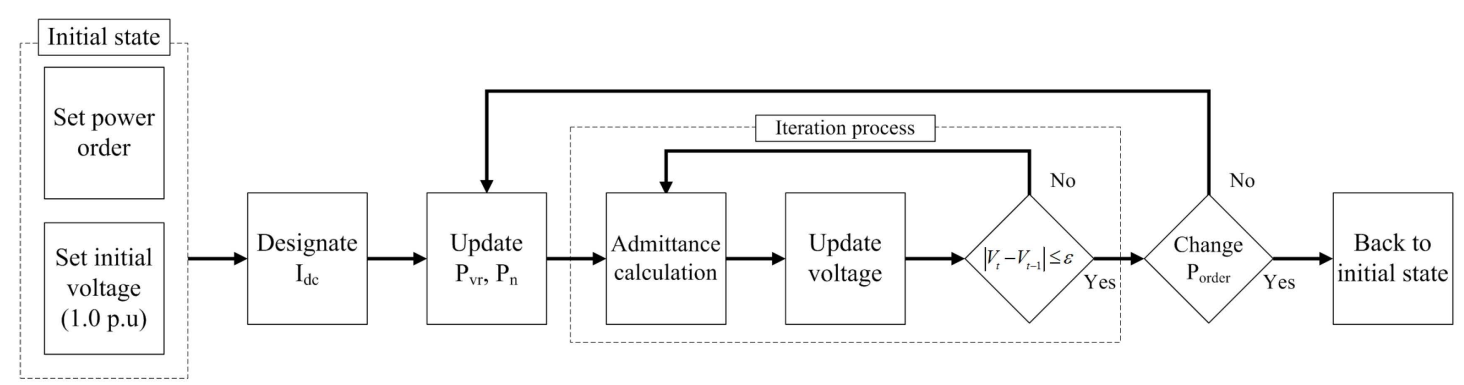

Figure 7. Power flow analysis algorithm of wave system including VR.

\subsection{Power Assignment Strategy}

The main objective of the previous power assignment strategy is to match the output profile of HGS at the PCC with the desired quantity. The total assignment process of the central algorithm handles the wind power expectation and pitch control to limit the generated quantity according to the designated signal by the operator when expecting an extra power quantity.

Figure 8 shows the real power control process of the HGS. The real power output is measured at the PCC and continuously assigns the maximum real power signal to each turbine, in the without constraint case, based on the state variables and expected wind speed. The calculation of the reference signal is obtained by applying the measured and predicted wind speed to the wind power curve. The wind power expectation is obtained from Equation (13):

$$
P=\left\{\begin{array}{cc}
0 & \left(v<v_{\text {in }} \text { or } v>v_{\text {out }}\right) \\
1 / 2 C_{\mathrm{p}} A \rho v^{3} & \left(v_{\text {in }} \leqslant v<v_{\mathrm{r}}\right) \\
1 / 2 C_{\mathrm{p}} A \rho v_{\mathrm{r}}{ }^{3} & \left(v_{\mathrm{r}} \leqslant v<v_{\text {out }}\right)
\end{array}\right.
$$

where $C_{\mathrm{p}}$ is the power coefficient; $A$ is the rotor swept area; $\rho$ is the air density; $v$ and $v_{\mathrm{r}}$ are the wind speed and rated wind speed and $v_{\text {in }}$ and $v_{\text {out }}$ are the cut-in wind speed and cut-out wind speed.

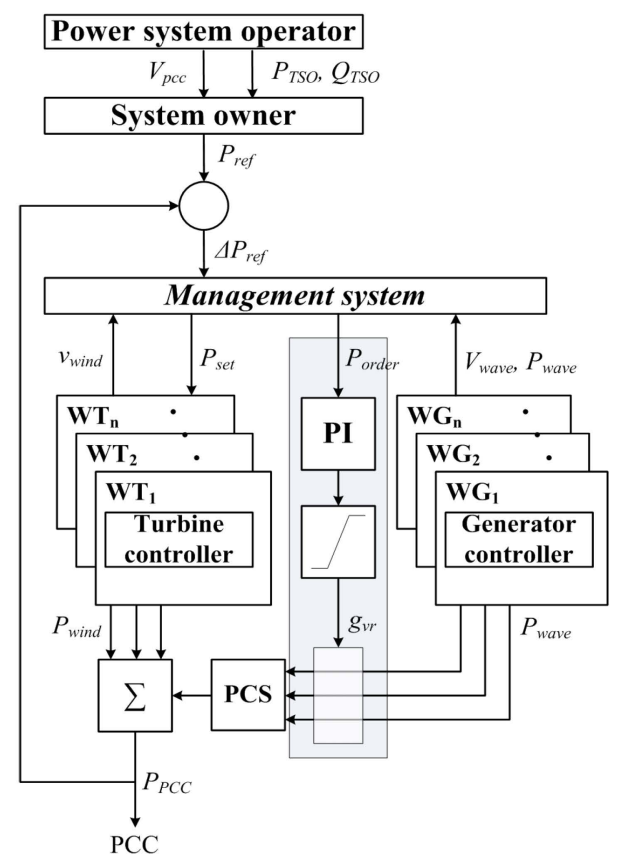

Figure 8. Real power control process of HGS. 
The highlighted section represents the portion of the proposed additional control in this paper. Compared with the previous system, the power control can manage the entire output power from PCS for the wave generators.

The voltage at the central station is continuously updated with the change of the output power of wave generators, and is easily utilized to generate the reference signal for variable resistance. With this process, flexible control can be obtained, and the maximization of available reactive power is feasible for the operation. The real power signals for each section are presented as follows:

$$
\begin{gathered}
\Delta P_{\text {ref }}=P_{\text {ref }}-P_{\text {pcc }} \\
P_{\mathrm{PCC}}=P_{\text {wind }}+P_{\text {wave }}-P_{\mathrm{vr}}
\end{gathered}
$$

where $P_{\text {ref }}$ is the real power order for entire HGS; $P_{\text {PCC }}$ is the total output power toward PCC; $P_{\text {wind }}$ is the real power order for wind system; and $P_{\text {wave }}$ is the real power order for wave generation system.

In the mode utilized in this paper, the identified control object is the appropriate admittance value within the mechanical constraint. Additionally, operation of a variable resistor to limit the power would generate losses in the form of heat like just other applications such as braking resistors [23]. Therefore, further analysis about cooling effects or current limitation are required in the demonstration process. The cooling effect which is closely related with the specification of the adopted device is not treated in this process of constitution, but the current limitation ranges are composed by considering the connected variable resistor. The suitable control time step differs according to the selected device's characteristics, but the minimum and maximum quantity of real power can be defined as follows:

$$
\begin{gathered}
P_{\mathrm{order}}^{\max }=g_{\mathrm{vr}}^{\max } \times\left(V_{\text {rate }}+\frac{I_{\mathrm{dc}}^{\max }}{g_{\text {eq }}}\right)^{2} \\
P_{\text {order }}^{\min }=g_{\mathrm{vr}}^{\min } \times V_{\text {rate }}{ }^{2} \\
I_{\mathrm{dc}}^{\max }=\frac{P_{\text {wave }}^{\max }}{V_{\text {rate }}}
\end{gathered}
$$

where $V_{\text {rate }}$ is the rated voltage of the DC network.

In the previous control logic, a lack of the priority of reactive power is shown in the control process because the maximum reactive power quantity of each wind turbine (the only controllable devices for real power) is determined by the real power output in the power factor $(P F)$ control, as defined in Equation (19):

$$
\left|Q_{\max }\right|=P_{\text {wind }} \tan \left(\cos ^{-1} P F\right)
$$

where $Q_{\max }$ is the maximum available reactive power.

By applying the real power management method in the wave generation system, the HGS can flexibly respond to real power orders. The option of fast performance with respect to the corresponding generated power with the reference signal would be preferable for the TSO. Moreover, if the TSO requests additional voltage compensation, the algorithm calculates each turbine's available control quantity by focusing on a balance point of the required real power and available reactive power. After finding the available control value, the algorithm determines the order of each generation system and assigns a reference signal for the system operation.

Basically, the system mainly considers the TSO order to respond to the grid requirement and the time interval between updating signals might be longer than the electrical operation. Therefore, the algorithm should quickly check the difference from the previous phase and proceed to the next sequence by minimizing the signal values. 


\section{Simulation}

\subsection{Simulation Configuration}

In order to check the output power and the followed state, the detailed information of the system must be formulated with the designed HGS. Table 1 presents the simulation layout of the HGS system used in this study. As mentioned above, the wave generators are comprised of two different arrays and are connected with the single PCS in the center of the station. It is assumed that the HGS is composed of four DFIG and 24 wave generators that are currently considered. The wind turbines adopted in the system are a 2-MW model [24], located at each vertex of the HGS. The equivalent source is incorporated by considering the short circuit ratio (SCR), which is used to estimate the system's robustness [25]. The transmission line data used in the simulation is shown in Table 2.

Table 1. Numerical data of the performed simulation.

\begin{tabular}{ccc}
\hline Specific data & Value & Unit \\
\hline Distance between wind turbines & 171.6 & $\mathrm{~m}$ \\
Distance between wave generators & 28.6 & $\mathrm{~m}$ \\
Distance from point of common coupling & 300 & $\mathrm{~m}$ \\
Rated AC voltage of inner system & 22.9 & $\mathrm{kV}$ \\
Rated DC voltage for wave system & 0.75 & $\mathrm{kV}$ \\
Number of wind turbines & 4 & - \\
Number of wave generators & 24 & - \\
Rated power of wind turbine & 2 & $\mathrm{MW}$ \\
Rated power of wave generator & 0.1 & $\mathrm{MW}$ \\
Short circuit ratio of utility grid & 15 & - \\
X/R ratio of utility grid & 15 & - \\
Variable resistance time interval & 0.05 & Second \\
\hline
\end{tabular}

Table 2. Numerical cable parameter in hybrid generation system (HGS).

\begin{tabular}{cccccc}
\hline $\begin{array}{c}\text { Voltage } \\
{[\mathbf{k V}]}\end{array}$ & $\begin{array}{c}\text { Size } \\
{\left[\mathbf{m}^{\mathbf{2}}\right]}\end{array}$ & $\begin{array}{c}\text { Allowable current } \\
{[\mathbf{A}]}\end{array}$ & $\begin{array}{c}\text { Conductor resistance } \\
{[\Omega / \mathbf{k m}]}\end{array}$ & $\begin{array}{c}\text { Inductance } \\
{[\mathbf{m H} / \mathbf{k m}]}\end{array}$ & $\begin{array}{c}\text { Capacitance } \\
{[\mu \mathbf{F} / \mathbf{k m}]}\end{array}$ \\
\hline 22.9 & 70 & 363 & 0.277 & 0.26 & 0.08 \\
$0.75(\mathrm{DC})$ & 35 & 228 & 0.565 & 0.277 & 0.08 \\
154 & 50 & 289 & 0.393 & 0.266 & 0.09 \\
\hline
\end{tabular}

The case studies consider two different environmental conditions by utilizing the weather data measured by the automatic weather system of the meteorological administration. To more suitably analyze the process of expanding the reserve, the system's operation was simulated, including the real power limitation section that is available to check the proposed control method. The total simulation time is $11 \mathrm{~s}$, which includes two seconds for the initialization and designated section for the proposed algorithm operation. By using the PSCAD, the composed system can be verified regarding the transient fluctuation with a reference signal by TSO.

The control adopting the proposed algorithm is performed with two different control modes, regarding the power limitation of the TSO order, whether or not RPR is considered. When a TSO sets the quantity of the output profile by referring to the pilot bus controller, the system should follow the reference value until the next signal generation. To consider the update cycle of the reference value which can differ according to the system characteristics, the case studies consider two different cycles for checking the availability in the case of a narrow interval. Table 3 presents information regarding the case studies in which the effect of the proposed algorithm is analyzed. 
Table 3. Reference signal change for case studies. Reactive power reserve: RPR.

\begin{tabular}{ccccc}
\hline Case & Order interval [s] & First order [MW] & Second order [MW] & RPR control [s] \\
\hline November & 10 & $8(2 \mathrm{~s})$ & - & $8.5 \sim 10$ \\
February & 5 & $8(2 \mathrm{~s})$ & $6(7 \mathrm{~s})$ & $6.5 \sim 10.5$ \\
\hline
\end{tabular}

\subsection{Simulation Results}

Figure 9 shows the original power curve of the first case (using weather data from November which has a high wind potential) by the HGS and the available reactive power curve is displayed with the normal control method. The historical value is applied on the entire simulation process and a classified sections that requiring real power control owing to wind fluctuation are extracted (including a significant decrease of wind speed). As mentioned above, the real power is continuously controlled according to the MPPT process by conversion system under the limitation signal. In this condition, to respond the operator orders, the exceeding profile above the reference signal was regulated through the pitch control process of the wind generation system. However, several real power excess points exist in the regulation section due to lack of the additional control method, and the available reactive power is fully dependent on the wind power control. To maximize the control ability of HGS and the RPR by utilizing the VSC of the wave generation system in the real power curtailment process, wave system control is applied in the second curtailment section (8.5-10 s).

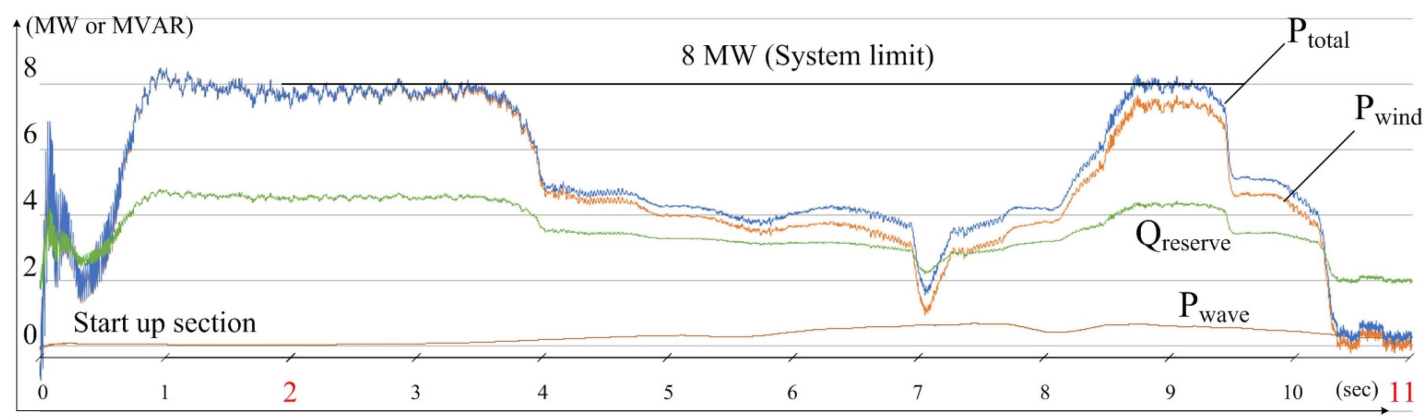

Figure 9. Output power and available reactive power curve of the HGS with previous control method (Case 1).

Figure 10 indicates the new power curve with the proposed algorithm for the same time period and operational conditions. As the PCS of wave system participates in the real power limitation process, the above power produced by the wave system is consumed at the connected resistor and the entire power of the HGS is appropriately managed compared to the previous condition. Furthermore, the reduction of real power generates additional RPR according to the capability characteristics of conversion system. The designated section shows a higher reserve quantity than the previous section. The real power profile of each generator is adjusted within the designated quantity as shown at the beginning and end parts of the highlighted control section. 


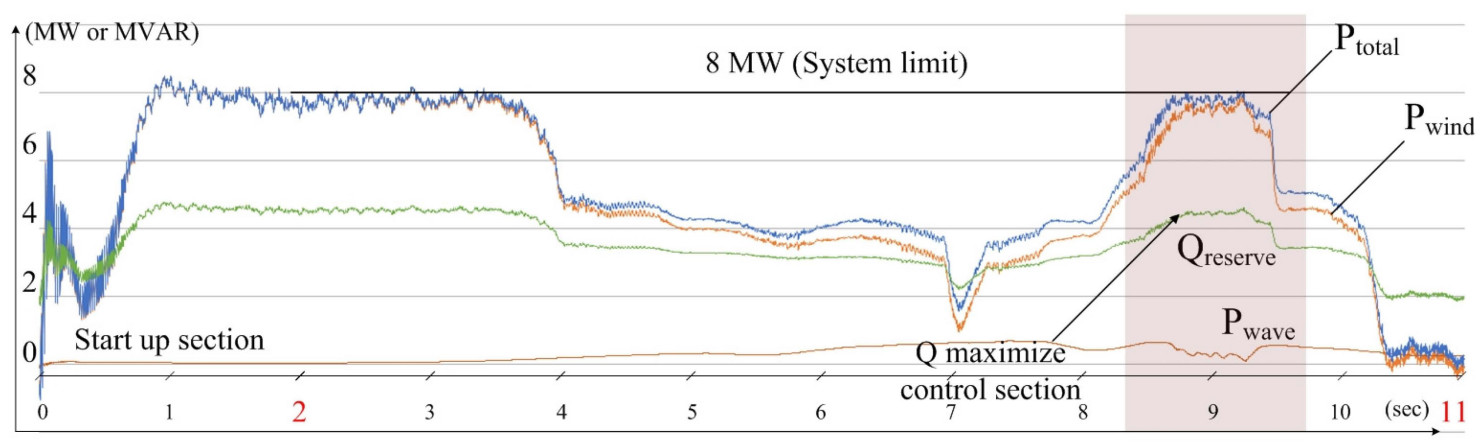

Figure 10. Output power and available reactive power curve of the HGS with proposed control method (Case 1).

Figures 11 and 12 show another case study analysis with February weather data. As in the first case, the effect of the proposed real power control is compared with the previous method which only utilizes a pitch control plan. The difference with the former is that the second system gave the signal of real power control with a $5 \mathrm{~s}$ cycle by TSO to consider the frequent changes in wind speed. There are two limitation sections that require a power control process, and the wave system operates to match with the order assigned by the operator as a controllable source. It can be confirmed that, as shown in Figure 12, the RPR is considered in both real power control sections by the proposed algorithm based on the system conditions.

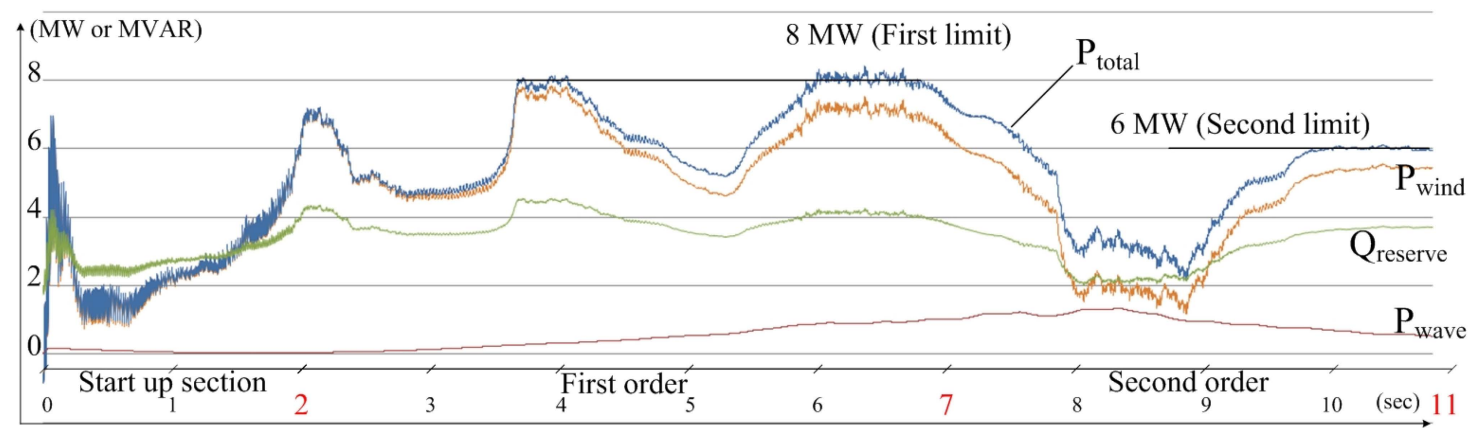

Figure 11. Output power and available reactive power curve of the HGS with previous control method (Case 2).

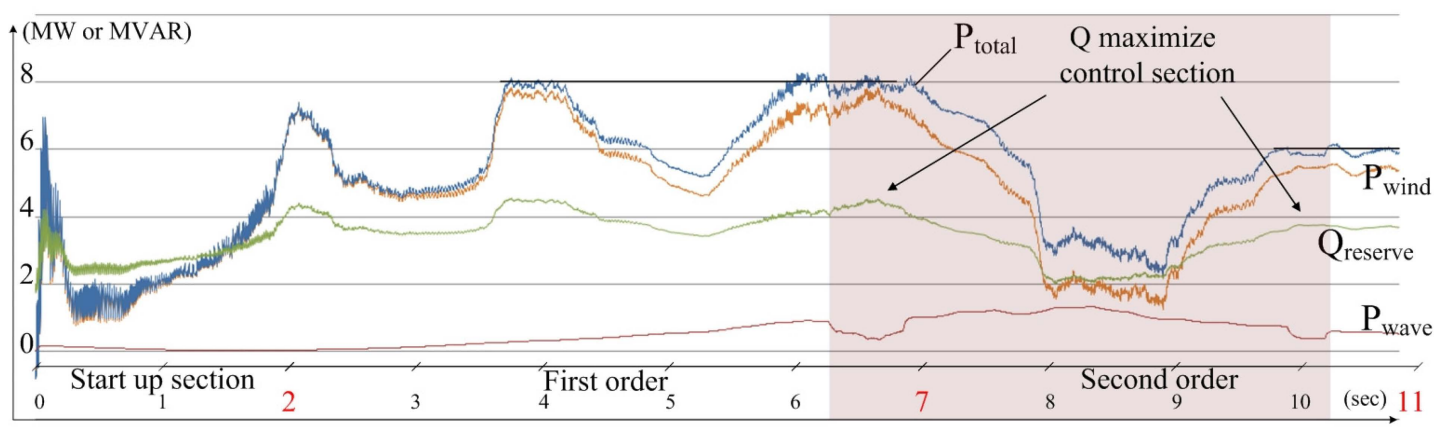

Figure 12. Output power and available reactive power curve of the HGS with proposed control method (Case 2).

Figure 13 shows the respective output profile of the wave power generators in the first array. The profiles of the output curves are similar due to the structural adjacency of the wave power 
generators, and the amplitude variation of the output power of the linear generator is generated based on the waveform data. The proposed output control of the wave power is given in a narrow section. Therefore, in order to confirm the operation, detailed graphs are shown in Figures 14-16. As the control quantity varies, the admittance values for power limitation were varied by considering the voltage variation. The values are designated within the designed constraint, and the voltage fluctuation at DC section due to the control process is also maintained within a reasonable range.

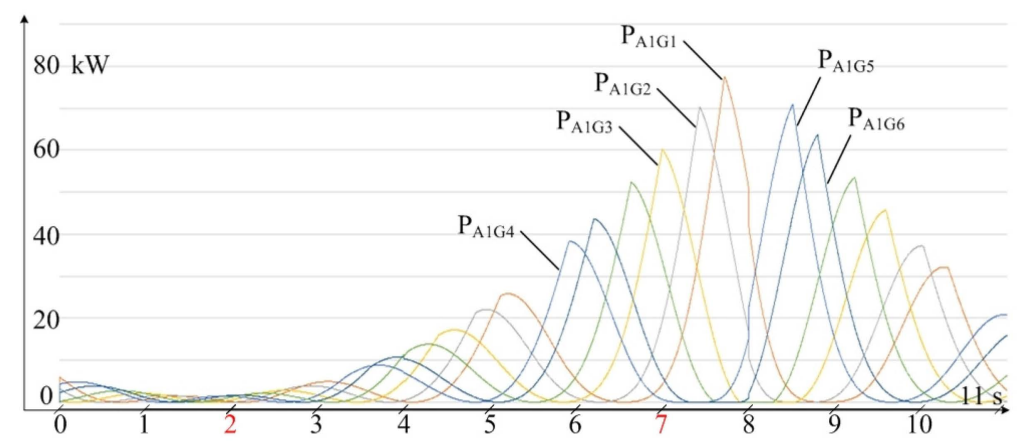

Figure 13. Output profile of wave generators in array 1. $P_{\mathrm{AlG} n}$ : real power output of generator $n$ in array $l$.

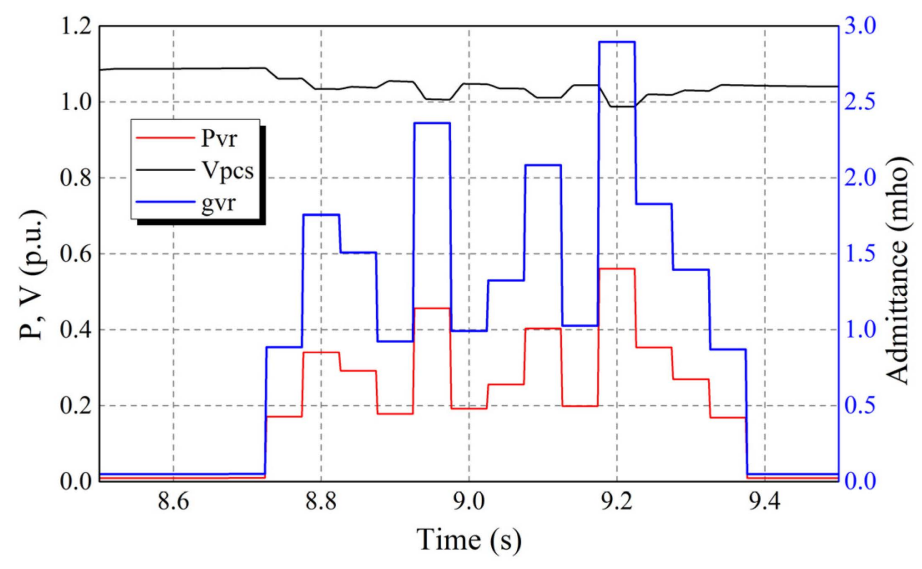

Figure 14. Admittance and pcs voltage variation in Case 1 (8.5-9.5 s).

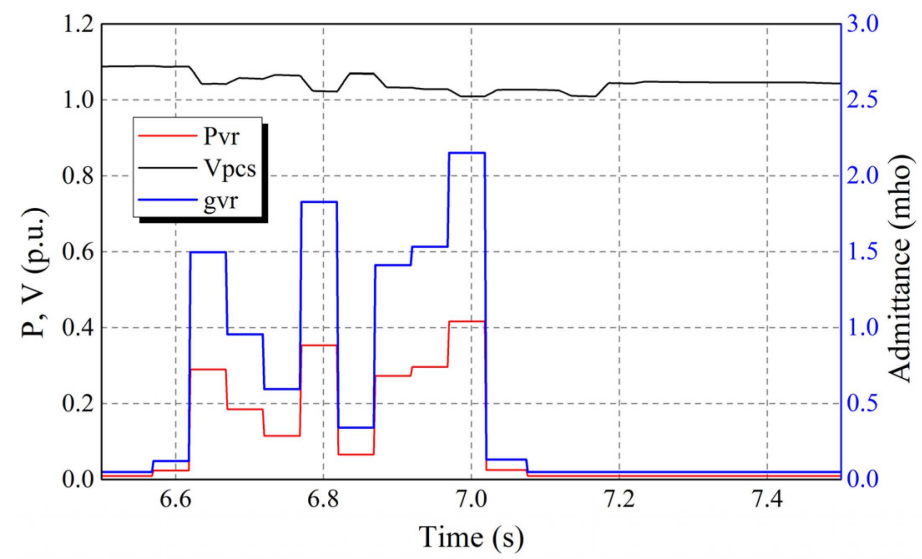

Figure 15. Admittance and pcs voltage variation in Case 2 (6.5-7.5 s). 


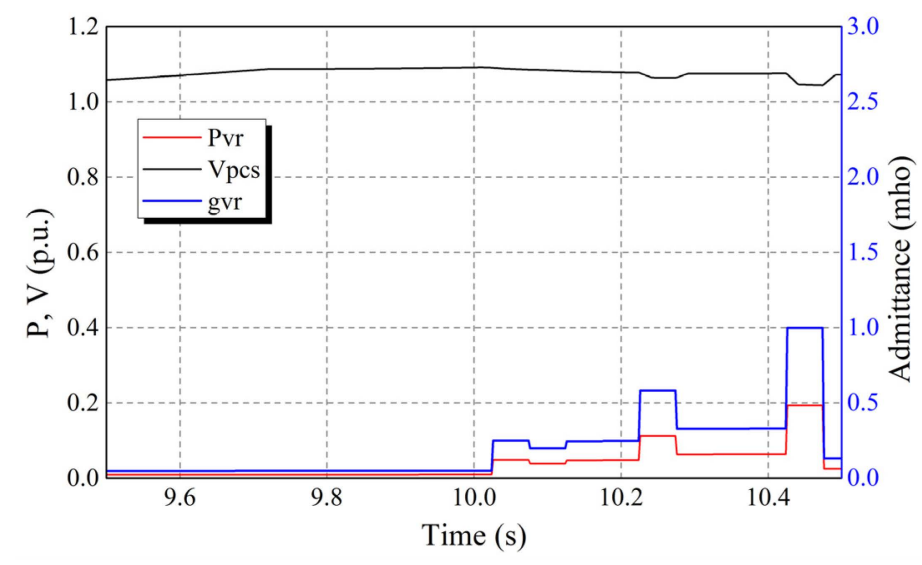

Figure 16. Admittance and pcs voltage variation in Case 2 (9.5-10.5 s).

The comparison with the previous system regarding RPR and the excess energy above the reference signal, the maximum controlled quantity due to the variable resistance while considering the admittance value are presented in Table 4. Not only does the method secure a higher available reactive power than that of the previous system, the control error (which refers to the output power above the TSO order) is lower than that of the previous system because the proposed plan controls the output power in both generation systems.

Table 4. Numerical results of the simulations. Volt-ampere reactive: MVAR.

\begin{tabular}{|c|c|c|c|c|c|c|}
\hline Case & & $\begin{array}{l}\text { Control } \\
\text { section }[s]\end{array}$ & $\begin{array}{l}\text { Average RPR } \\
\text { [MVAR] }\end{array}$ & $\begin{array}{c}\text { Control error } \\
{[\mathrm{Wh}]}\end{array}$ & $\begin{array}{l}\text { Maximum controlled } \\
\text { power }[\mathrm{kW}]\end{array}$ & $\begin{array}{l}\text { Maximum } \\
\text { admittance value }[\mho]\end{array}$ \\
\hline \multirow{2}{*}{1 (November) } & Previous & $8.75-9.33$ & 4.2795 & 21.6 & - & - \\
\hline & \multicolumn{2}{|c|}{ Improvement } & 0.1411 & -17 & - & - \\
\hline \multirow{5}{*}{2 (February) } & Previous & $6.2-6.8$ & 4.3015 & 20.6 & - & - \\
\hline & Adopt & $6.2-6.8$ & 4.51 & 4.7 & 416.5 & 2.1512 \\
\hline & Previous & $10.55-11$ & 3.8404 & 20 & - & - \\
\hline & Adopt & $10.55-11$ & 3.924 & 15 & 193.31 & 0.9985 \\
\hline & \multicolumn{2}{|c|}{ Improvement } & 0.0836 & -5 & - & - \\
\hline
\end{tabular}

\section{Conclusions}

This paper suggests a new power control algorithm for the HGS to respond to the various situations more flexibly with a variable resistance device as an exemplary case. The proposed algorithm shows contributions in terms of the response of the TSO order in the case studies. Due to the variation of the TSO order, the system changes the reference signal by calculating the available control values and adopting them to secure available reactive power. It was difficult to demonstrate the significant effect of the control method regarding wave generation systems because the ongoing project is being exemplified on a beach near the coast, which means the total output power of wave generators is smaller than the general state of real sea waves. Since the output power of the wave generator under normal conditions is low, the effect of the proposed plan seems insignificant. Nevertheless, for composing a large scale system with a number of HGSs, an additional control method for the wave generation system is required. The impact of the algorithm would be considerable with the high penetration of the HGS. Small-scale RPR compensation might be useful for the large-scale offshore generator system. As mentioned at the introduction part, the DC section analysis is adjustable in ESS applications because the charging/discharging process of storage also should consider the voltage variations caused by the operating conditions. 
Acknowledgments: This work was supported by the MOF grant (Development of Design Technologies for a 10 MW Class Wave and Offshore Wind Hybrid Power Generation System and Establishment of the Sea Test Infrastructure) and by Human Resources Development of KETEP grant (No. 20134030200340) funded by the Korean government Ministry of Knowledge Economy.

Conflicts of Interest: The authors declare no conflict of interest.

\section{References}

1. Kusiak, A.; Zheng, H.; Song, Z. Short-Term prediction of wind farm power: A data mining approach. IEEE Trans. Energy Convers. 2009, 24, 125-136. [CrossRef]

2. Morales, A.; Robe, X.; Sala, M.; Prats, P.; Aguerri, C.; Torres, E. Advanced grid requirements for the integration of wind farms into the Spanish transmission system. IET Renew. Power Gener. 2008, 2, 47-57. [CrossRef]

3. Dvorak, M.J.; Archer, C.L.; Jacobson, M.Z. California offshore wind energy potential. Renew. Energy 2010, 35, 1244-1254. [CrossRef]

4. Ullah, N.R.; Bhattacharya, K.; Thiringer, T. Wind farms as reactive power ancillary service providers-Technical and economic issues. IEEE Trans. Energy Convers. 2009, 24, 661-672. [CrossRef]

5. Liang, L.; Jianlin, L.; Dong, H. An optimal energy storage capacity calculation method for $100 \mathrm{MW}$ wind farm. In Proceedings of the International Conference on Power System Technology, Hangzhou, China, 24-28 October 2010; pp. 1-4.

6. Hartmann, B.; Dan, A. Cooperation of a Grid-connected wind farm and an energy storage unit-Demonstration of a simulation tool. IEEE Trans. Sustain. Energy 2012, 3, 49-56. [CrossRef]

7. Dicorato, M.; Forte, G.; Trovato, M. Voltage compensation for wind integration in power systems. In Proceedings of the 3rd IEEE International Symposium on Power Electronics for Distributed Generation Systems (PEDG), Aalborg, Denmark, 25-28 June 2012; pp. 464-469.

8. Wang, L.; Li, H.W.; Wu, C.H.T. Stability Analysis of an integrated offshore wind and seashore wave farm fed to a power grid using a unified power flow controller. IEEE Trans. Power Syst. 2013, 28, 2211-2221. [CrossRef]

9. Stoutenburg, E.D.; Jacobson, M.Z. Reducing offshore transmission requirements by combining offshore wind and wave farms. IEEE J. Ocean. Eng. 2011, 36, 552-561. [CrossRef]

10. Beerens, J. Offshore hybrid wind-wave energy converter system. Master's Thesis, Delft University of Technology, Delft, The Netherlands, 26 February 2010.

11. Hansang, L.; Hanmin, L.; Changmu, L.; Gilsoo, J.; Gildong, K. Energy storage application strategy on DC electric railroad system using a novel railroad analysis algorithm. J. Electr. Eng. Technol. 2010, 5, 228-238.

12. Kim, K.H.; Lee, K.; Sohn, J.M.; Park, S.W.; Choi, J.S.; Hong, K.Y. Conceptual design of 10 MW class floating wave-offshore wind hybrid power generation system. In Proceedings of the 25 International Offshore and Polar Engineering Conference, Kona, HI, USA, 21-26 June 2015.

13. Bunjongjit, K.; Kumsuwan, Y.; Sriuthaisiriwong, Y. An implementation of three-level BTB NPC voltage source converter based-PMSG wind energy conversion system. In Proceedings of the TENCON 2014-2014 IEEE Region 10 Conference, Bangkok, Thailand, 22-25 October 2014; pp. 1-5.

14. Aubry, J.; Ben Ahmed, H.; Multon, B. Sizing optimization methodology of a surface permanent magnet machine-converter system over a torque-speed operating profile: Application to a wave energy converter. IEEE Trans. Ind. Electron. 2012, 59, 2116-2125. [CrossRef]

15. Rabiee, A.; Soroudi, A. Stochastic multiperiod OPF model of power systems with HVDC-connected intermittent wind power generation. IEEE Trans. Power Deliv. 2014, 29, 336-344. [CrossRef]

16. Shin, H.J.; Choi, J.Y.; Park, Y.S.; Koo, M.M.; Jang, S.M.; Han, H. Electromagnetic Vibration Analysis and Measurements of Double-Sided Axial-Flux Permanent Magnet Generator with Slotless Stator. IEEE Trans. Magn. 2014, 50. [CrossRef]

17. Van Cutsem, T.; Vournas, C. Voltage Stability of Electric Power Systems; Kluwer Academic Publisher: Norwell, MA, USA, 1998.

18. Mousavi, O.A.; Bozorg, M.; Ahmadi-Khatir, A.; Cherkaoui, R. Reactive power reserve management: Preventive countermeasure for improving voltage stability margin. In Proceedings of the IEEE Power and Energy Society General Meeting, San Diego, CA, USA, 22-26 July 2012; pp. 1-7. 
19. Cardenas, R.; Pena, R.; Wheeler, P.; Clare, J.; Asher, G. Control of the reactive power supplied by a WECS based on an induction generator fed by a matrix converter. IEEE Trans. Ind. Electron. 2009, 56, 429-438. [CrossRef]

20. Jasinski, M.; Dariusz, S.; Kazmierkowsk, M.P. Direct active and reactive power control of AC/DC/AC converter with permanent magnet synchronous generator for sea wave converter. In Proceedings of the International Conference on Power Engineering, Setubal, Portugal, 12-14 April 2007; pp. 78-83.

21. Zhang, L.; Sun, K.; Xing, Y.; Feng, L.; Ge, H. A modular grid-connected photovoltaic generation system based on DC bus. IEEE Trans. Power Electron. 2011, 26, 523-531. [CrossRef]

22. Eriksson, M.; Waters, R.; Svensson, O.; Isberg, J.; Leijon, M. Wave power absorption: Experiments in open sea and simulation. J. Appl. Phys. 2007, 102. [CrossRef]

23. Wang, W.; Cheng, M.; Wang, Y.; Zhang, B.; Zhu, Y.; Ding, S.; Chen, W. A novel energy management strategy of onboard supercapacitor for subway applications with permanent-magnet traction system. IEEE Trans. Veh. Technol. 2014, 63, 2578-2588. [CrossRef]

24. Pujante-López, A.J.; Gómez-Lázaro, E.; Fuentes-Moreno, J.A.; Molina-García, A.; Vigueras-Rodríguez, A. Performance comparison of a 2 MW DFIG wind turbine model under wind speed variations. In Proceedings of the European Wind Energy Conference and Exhibition, Marseille, France, 16-19 March 2009.

25. Nayak, O.B.; Gole, A.M.; Chapman, D.G.; Davies, J.B. Dynamic performance of static and synchronous compensators at an HVDC inverter bus in a very weak AC system. IEEE Trans. Power Syst. 1994, 9, 1350-1358. [CrossRef]

(C) 2015 by the authors; licensee MDPI, Basel, Switzerland. This article is an open access article distributed under the terms and conditions of the Creative Commons by Attribution (CC-BY) license (http://creativecommons.org/licenses/by/4.0/). 